Note

\title{
Infarction Followed by Hemorrhage in Pituitary Adenoma due to Endocrine Stimulation Test
}

\author{
IIChIRo MATSUURA, NAOKATSU SAEKI, Motoo KUBOTA, HisAYUKi MURAI aNd AKIRA YAMAURA \\ Department of Neurological Surgery, Chiba University School of Medicine, Chiba 260-8670, Japan
}

\begin{abstract}
A 63-year-old man, who presented with visual field loss due to pituitary tumor, received an intravenous bolus injection of thyrotropin and gonadotropin releasing hormones and insulin as a preoperative evaluation. He complained of severe headache and nausea 2 hours after injection. Emergent CT scan showed no evidence of intratumoral hemorrhage. The next day, his visual field became null. MR images revealed heterogeneous mixed intensity lesions. Under diagnosis of pituitary apoplexy, he underwent transsphenoidal tumor removal 30 hours after onset. Intraoperative and pathological findings showed tumor hemorrhage and adjacent necrotic change. Fourteen cases with sufficient clinical detail in the literature are reviewed: All of the cases had macroadenoma with suprasellar extension. Testing agents were gonadotropin and thyrotropin releasing hormones in $92.9 \%$ and $85.7 \%$ of cases, respectively. Headache was an initial symptom and started within two hours in all cases but one. Half of the cases showed no change on CT scan. However, tumor hemorrhage was evidenced in $92.9 \%$ of cases with or without necrosis due to ischemic change, intraoperatively or pathologically. It is speculated that pituitary apoplexy often starts with infarction possibly due to vasoactive effect of testing agents and later develops into hemorrhage. Therefore, it is necessary to observe patients closely at least a few hours after endocrine stimulation test, and MR imaging may make an earlier diagnosis for the pituitary apoplexy since CT scan often shows no density change in the pituitary adenoma.
\end{abstract}

Key words: Pituitary apoplexy, Endocrine stimulation test, Macroadenoma, Neuroimaging

(Endocrine Journal 48: 493-498, 2001)

PITUITARY apoplexy is a well-known syndrome caused by the sudden expansion of preexisting pituitary tumor due to hemorrhage and/or infarction. Its clinical characteristics are sudden onset of severe headache, nausea, confusion, visual disturbance and ophthalmoplegia. Although endocrine stimulation test is known to be one of the precipitating factors associated with pituitary apoplexy, its pathogenesis has been unclarified. We report a case of adenoma infarction followed by hemorrhage, which occurred after bolus injection of hypothalamic hormones and

Received: March 7, 2001

Accepted: May 2, 2001

Correspondence to: Dr. Naokatsu SAEKI, Department of Neurological Surgery, Chiba University School of Medicine Inohana 1-8-1, Chuo-ku, Chiba 260-8670, Japan insulin as a preoperative evaluation to pituitary macroadenoma. The purpose of this report is to elucidate the clinical characteristics of pituitary apoplexy and its pathomechanism after endocrine stimulation test.

\section{Case report}

A 63-year-old man was referred to our hospital with a two-month history of visual field defect and decreased visual acuity. He had no other neurological disorders or endocrinological symptoms in the physical examination. On admission his height was $168 \mathrm{~cm}$ and his weight $64.4 \mathrm{~kg}$. Blood pressure was $130 / 90 \mathrm{mmHg}$, pulse $60 \mathrm{bpm}$. Visual acuity was $20 / 20$ in the right eye and $8 / 20$ in the left. Visual 
field examination revealed nasal hemianopia on the left side. Extraocular movements were normal. Baseline levels of anterior pituitary hormones were as follows: growth hormone $(\mathrm{GH}) 0.21 \mathrm{ng} / \mathrm{ml}$, prolactin (PRL) $23.53 \mathrm{ng} / \mathrm{ml}$, thyroid-stimulating hormone (TSH) $1.17 \mu \mathrm{U} / \mathrm{ml}$, follicle-stimulating hormone (FSH) $15.39 \mathrm{mIU} / \mathrm{ml}$, luteinizing hormone (LH) 1.10 $\mathrm{mIU} / \mathrm{ml}$, adrenocorticotropic hormone (ACTH) 47.8 $\mathrm{pg} / \mathrm{ml}$.

Plain skull X-ray images revealed a "ballooning" and "double floor" of sellae turcica. Magnetic resonance (MR) images showed a pituitary tumor with suprasellar extension (Fig. 1A, B, C), and computed tomography (CT) scan showed a slightly high density mass at the sellae turcica (Fig. 2A).
As preoperative endocrine evaluation, he received an intravenous bolus injection of $500 \mu \mathrm{g}$ thyrotropin releasing hormone (TRH), $100 \mu \mathrm{g}$ gonadotropin releasing hormone $(\mathrm{GnRH})$, and 6.5 units regular insulin $(0.1$ units $/ \mathrm{kg})$. Two hours after the injection, he complained of severe headache and nausea that persisted all day long. Emergent CT scan images six hours after onset showed no evidence of intratumoral hemorrhage or increase of tumor size (Fig. 2B). Neither his visual field nor acuity deteriorated. Then the next day, he woke up to find that his left vision was null. The light reflex had disappeared in his left eye. Emergent MR imaging was performed at 24 hours after onset revealed a lesion of heterogeneous high and low signal- intensity in the tumor (Fig. 3A,

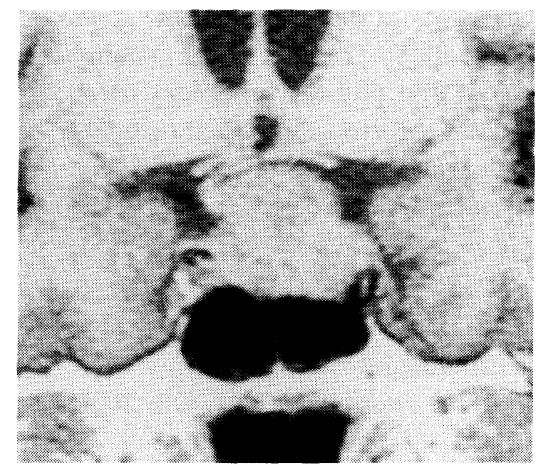

A

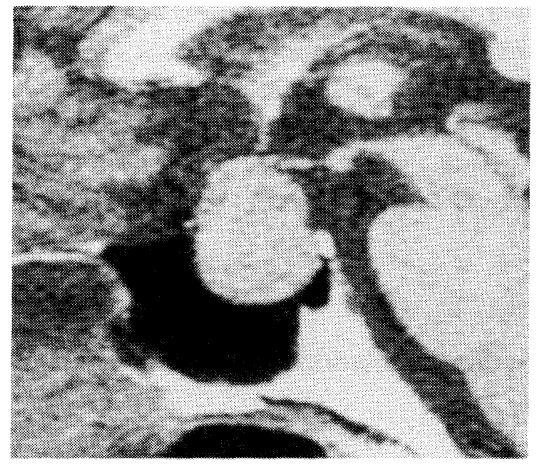

B

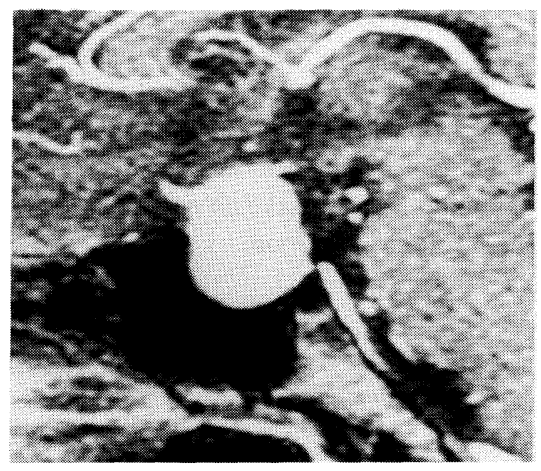

C

Fig. 1. A, B: Coronal and sagittal T1-weighted MR images show isointense pituitary macroadenoma with suprasellar extension and displacement of optic chiasm.

C: Sagittal Gd-DTPA enhanced MR image shows the homogeneous enhancement of pituitary macroadenoma.

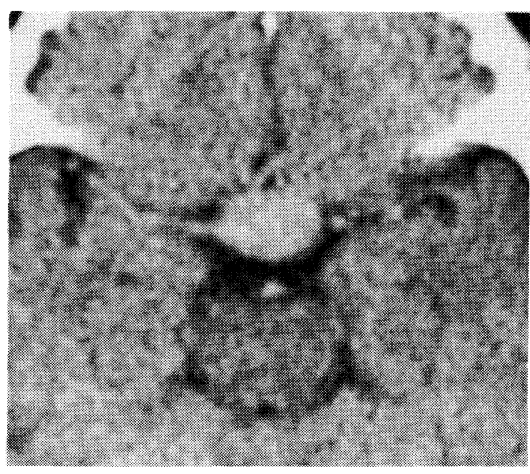

A

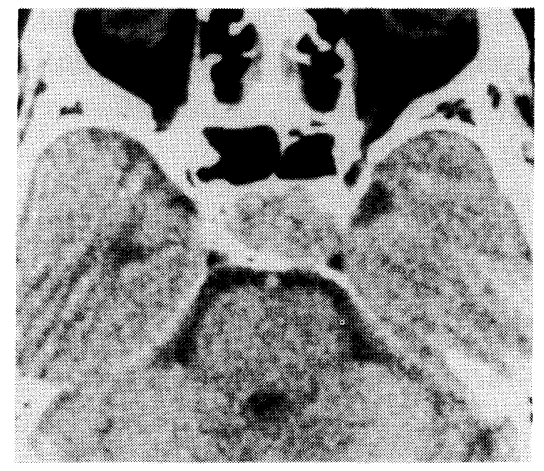

B

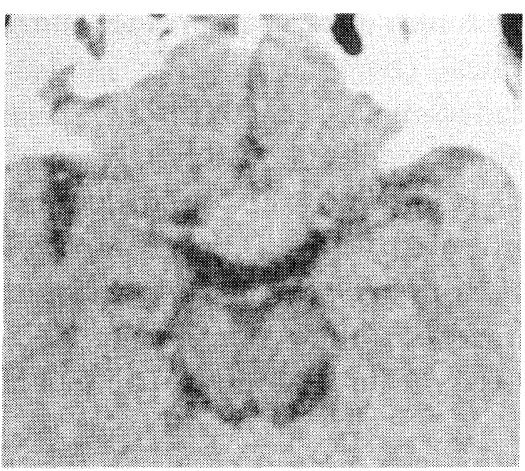

C

Fig. 2. A: Plain computed tomography (CT) scan images show a slightly high-density mass lesion in the suprasellar cistern. B: Emergent CT scan images (6 hours after onset) show neither intratumoral hemorrhage nor expansion of pituitary adenoma. 


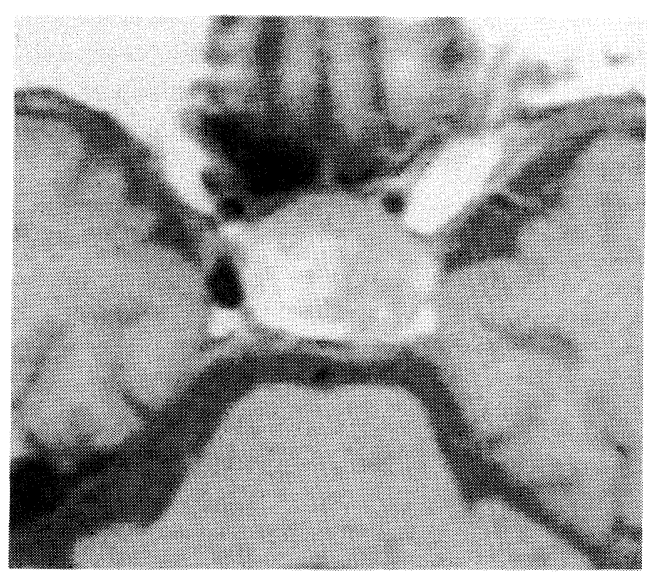

A

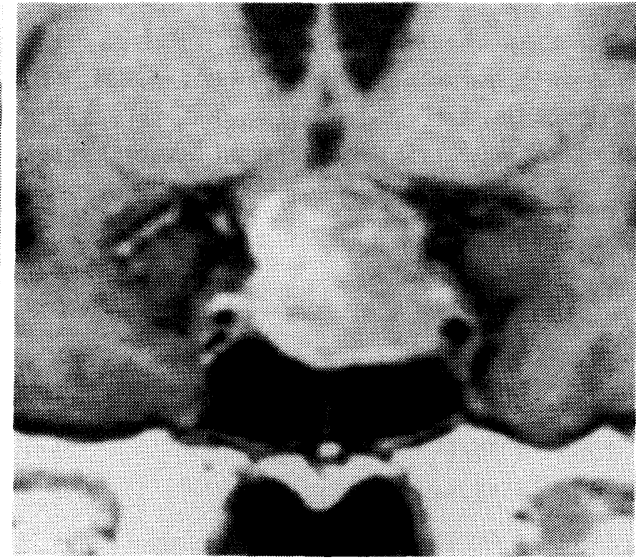

B

Fig. 3. Emergent axial (A) and coronal (B) MR images reveal a lesion of heterogeneous high- and low signal-intensity in the pituitary macroadenoma.

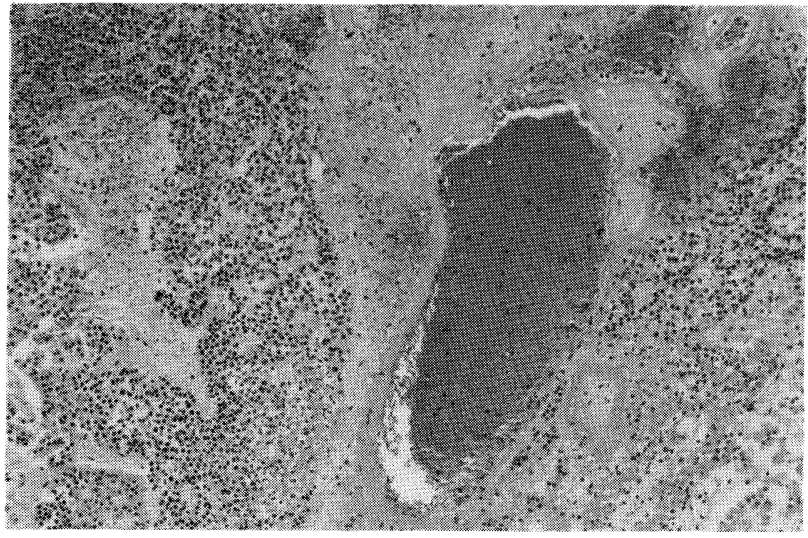

Fig. 4. Photograph of specimen stained with hematoxylin and eosin (X150). Hemorrhage and adjacent necrotic area is seen in the papillary choromophobe adenoma.

B). Thirty hours later, the tumor was removed via transsphenoidal approach. Incision of dura mater revealed obvious intratumoral hemorrhage, and the pituitary macroadenoma was subtotally removed. Histological examination revealed hemorrhage and adjacent necrotic area in the papillary type chromophobe adenoma. The adenoma was not especially vessel-rich, and the necrotic area was compatible with an infarction. (Fig. 4)

After the operation, headache and nausea improved. Visual field and acuity improved to the level of preoperative state at a 6-month postoperative ophthalmological examination. Postoperative MR image showed a near total removal of the adenoma.

\section{Discussion}

The cause of pituitary apoplexy is considered to be an endocrine stimulation test in this case, since the headache and subsequent ophthalmological deterioration occurred immediately after the test.

Although causes of pituitary apoplexy are not sufficiently elucidated, there are many precipitating factors such as bromocriptine therapy, estrogen treatment, radiation therapy, head trauma, anticoagulant therapy, pregnancy, angiography, cerebral aneurysm, lumbar puncture, myelography, pneumoencephalography, increased intracranial pressure, nasal catarrh and open heart surgery [1, 2]. While endocrine stimulation test is included as a one of the causes, how frequently the pituitary apoplexy occurs due to the test is unknown.

We reviewed the 13 cases in the literature, that had details of the following clinical data. 1. Hypothalamic hormones and/or insulin were used as the endocrine stimulating agents. 2. Pituitary apoplexy was confirmed in operative and/or pathological findings. A total of 14 cases including our own were reviewed and their clinical features are summarized (Table 1) [1-12]. Patients were 9 males and 5 females, from 28 to 71 years of age (mean, 49.6 years). The diagnoses were 7 nonfunctioning adenomas, 
Table 1. Reported cases of pituitary apoplexy with pathological and/or operative evidence after endocrine stimulation test Abbreviations. F: female, M: male, TRH: thyrotropin-releasing hormone, GnRH: gonadotropin-releasing hormone, GRF: growth hormone releasing factor, $\mathrm{CRH}$ : corticotropin releasing hormone, FSH: follicle-stimulating hormone, PRL: prolactin, GH: growth hormone, CT: computed tomography, MRI: magnetic resonance imaging, T1WI: T1weighted image, SAH: subarachnoid hemorrhage, $\bigcirc$ : no description about doses.

\begin{tabular}{|c|c|c|c|c|c|c|c|c|c|c|}
\hline \multicolumn{2}{|l|}{ Case } & \multicolumn{4}{|c|}{ Clinical profiles } & \multicolumn{5}{|c|}{ Stimulating agents } \\
\hline No. Author & Year & $\begin{array}{l}\text { Age/ } \\
\text { Gender }\end{array}$ & Diagnosis & $\begin{array}{c}\text { Suprasellar } \\
\text { extension }\end{array}$ & $\begin{array}{l}\text { Visual } \\
\text { symptom }\end{array}$ & $\begin{array}{l}\text { TRH } \\
(\mu \mathrm{g})\end{array}$ & $\underset{(\mu \mathrm{g})}{\mathrm{GnRH}}$ & $\begin{array}{l}\text { Insulin } \\
\text { (unit/kg) }\end{array}$ & $\begin{array}{l}\text { GRF } \\
(\mu \mathrm{g})\end{array}$ & $\underset{(\mu \mathrm{g})}{\mathrm{CRH}}$ \\
\hline 1. Bernstein & 1984 & $48 / \mathrm{M}$ & not described & + & + & 200 & 100 & 0.1 & & \\
\hline 2. Korsic & 1984 & $56 / \mathrm{M}$ & FSHoma & + & + & & 100 & & & \\
\hline 3. Chapman & 1985 & $39 / F$ & PRLoma & + & - & 200 & 100 & 0.15 & & \\
\hline 4. Masson & 1993 & $54 / \mathrm{M}$ & FSHoma & + & + & & 100 & & & \\
\hline 5. Okuda & 1994 & $60 / F$ & non-functioning & + & - & 500 & 100 & 0.1 & & \\
\hline 6. Masago & 1995 & $48 / \mathrm{M}$ & non-functioning & + & + & 500 & 100 & 0.1 & & \\
\hline 7. Masago & 1995 & $54 / \mathrm{M}$ & non-functioning & + & + & 500 & 100 & & & \\
\hline 8. Szabolcs & 1997 & $54 / \mathrm{M}$ & non-functioning & + & - & 200 & & & & \\
\hline 9. Otsuka & 1998 & $31 / \mathrm{F}$ & GHoma & + & + & 100 & 20 & & 20 & 20 \\
\hline 10. Dökmetas & 1999 & $28 / \mathrm{F}$ & GHoma & + & + & 200 & & & & \\
\hline 11. Sanno & 1999 & $55 / \mathrm{M}$ & non-functioning & + & - & 500 & 100 & & 100 & 100 \\
\hline 12. Lee & 2000 & $34 / \mathrm{M}$ & GHoma & + & - & 400 & 100 & 0.15 & & \\
\hline 13. Riedl & 2000 & $71 / \mathrm{F}$ & non-functioning & + & + & 0 & 0 & & 0 & O \\
\hline 14. Our case & 2001 & $63 / \mathrm{M}$ & non-functioning & + & + & 500 & 100 & 0.1 & & \\
\hline
\end{tabular}

3 GH secreting, 2 FSH secreting, 1 PRL secreting and 1 without description. Although all cases had macroadenoma with suprasellar extension, 5 cases had no visual disturbance. This suggests that pituitary apoplexy may occur even in macroadenomas that are not large enough to compress the optic pathway or induce visual symptoms.

With respect to the endocrine stimulating agents, GnRH (92.9\%), and TRH (85.7\%) were most commonly used. The combinations of testing agents used were as follows: TRH $+\mathrm{GnRH}+$ insulin (6 cases), TRH $+\mathrm{GnRH}+\mathrm{GRF}+\mathrm{CRH}$ ( 3 cases), TRH + GnRH ( 2 cases), GnRH ( 2 cases), and TRH (1 case).

Initial symptoms were as follows: headache in all $(100 \%)$ cases, visual symptoms in $4(28.6 \%)$ cases, nausea in $4(28.6 \%)$ cases, vomiting in $4(28.6 \%)$ cases and chest discomfort or oppression in 2 $(14.3 \%)$ cases. Deteriorated consciousness, confu- sion, sweating and burning sensation were noted in 1 (7.1\%) case each. Although visual acuity and field impairment as well as ophthalmoplegia are confirmatory signs for pituitary apoplexy, only headache without other ophthalmologic impairment is common as the first clinical sign of pituitary apoplexy after endocrine stimulation tests.

The interval from administration of agents to onset of initial symptom ranged from 2 minutes to 2 hours, but 1 case of Dökmetas et al. reported an apoplexy at 88 hours after hormone function test [4]. Considering the most common time of occurrence of pituitary apoplexy, it is necessary to observe patients closely at least for a few hours after endocrine stimulation test.

In literature review, tumor hemorrhage was evidenced in 13 (92.9\%) cases during operation or in pathological study, and was much more common than infarction alone. However, in our case, CT 


\begin{tabular}{|c|c|c|c|c|c|}
\hline \multicolumn{4}{|c|}{ Clinical features of pituitary apoplexy } & \multicolumn{2}{|c|}{ Evidence of pituitary apoplexy } \\
\hline Initial symptom & Time to onset & CT scan/Time & MRI & $\begin{array}{l}\text { Hemorrhage } \\
\text { on surgery }\end{array}$ & Pathology \\
\hline headache, blurred vision & $5 \mathrm{~min}$ & no change/day 0 & - & not described & infarction \\
\hline headache, confusion & $120 \mathrm{~min}$ & heterogeneous/day 1 & - & not described & hemorrhage \\
\hline headache & $40 \mathrm{~min}$ & low density/day 3 & - & + & infarction \& hemorrhage \\
\hline headache, vomiting & $20 \mathrm{~min}$ & low/day 0 & - & + & not described \\
\hline headache, sweating, nausea & $10 \mathrm{~min}$ & high with SAH/day 0 & - & with $\stackrel{+}{\text { SAH }}$ & hemorrhage \\
\hline headache, blurred vision & $15 \mathrm{~min}$ & no change/day 0 & - & + & hemorrhage \\
\hline $\begin{array}{l}\text { burning sensation, } \\
\text { headache, blurred vision, } \\
\text { chest discomfort }\end{array}$ & $10 \mathrm{~min}$ & no change/day 0 & - & $\begin{array}{l}\text { not described } \\
\text { (necrotic) }\end{array}$ & hemorrhage \\
\hline headache, vomiting & $60 \mathrm{~min}$ & high/day 1 & - & + & hemorrhage \\
\hline $\begin{array}{l}\text { headache, nausea } \\
\text { chest oppression }\end{array}$ & $2 \min$ & high with SAH/day 0 & - & with $\stackrel{+}{\text { SAH }}$ & not described \\
\hline $\begin{array}{l}\text { headache, nausea, } \\
\text { vomiting, visual disturbance, } \\
\text { deteriorated consciousness }\end{array}$ & 88 hours & high/day 5 & - & + & hemorrhage \\
\hline headache & $30 \mathrm{~min}$ & $\begin{array}{l}\text { no change/day } 0 \\
\text { high with SAH/day } 1\end{array}$ & - & $\stackrel{+}{+}$ & necrosis \\
\hline headache, vomiting & $20 \mathrm{~min}$ & $\begin{array}{l}\text { no change/day } 0 \\
\text { (enhanced CT) }\end{array}$ & heterogeneous & + & infarction \& hemorrhage \\
\hline headache & during test & no change/day 1 & high intensity & not described & hemorrhage \\
\hline headache, nausea & $120 \mathrm{~min}$ & no change/day 0 & high intensity & + & infarction \& hemorrhage \\
\hline
\end{tabular}

scan did not reveal either density or size changes in the initial study. In the literature as well, the CT findings obtained within 5 days after onset of initial symptoms were as follows: high density in 4 cases, low density in 2, mixed density in 1 and no change in 7. It should be noted that CT scans at acute stage fail to demonstrate specific signs of pituitary apoplexy in about half of the cases. On the contrary, MR imaging was performed in 3 reported cases including our own case without any change on CT scans. All of them showed high and/or mixed intensity on T1-weighted images. Thus CT scan is often useless in detecting early changes of pituitary apoplexy, while MR imaging is useful in early diagnosis of pituitary apoplexy. In addition, it is worthwhile to try diffusion weighted MR imaging which is superior to conventional MR imaging diagnosing at acute phase of cerebral infarction [13].

Various hemorrhagic and ischemic pathomecha- nisms have been suggested for the development of pituitary apoplexy [14]. Fragile vascular walls of adenomas more readily rupture and cause intratumor hemorrhage. Large adenoma may outgrow their blood supply and develop areas of ischemic necrosis. The trabecular arteries (branches of the superior hypophyseal artery) may be compressed by the adenoma and diaphragm sellae. These mechanisms may result in primary ischemia and secondary necrosis of the tumor. Finally the infarction may be followed by intratumoral hemorrhage [14]. Although similar underlying pathomechanisms may be applicable, the details of pituitary apoplexy after hormone stimulation test have yet to be specified. In this study, based on chronological neuroimaging data and pathological findings, it is clearly demonstrated that the pituitary apoplexy following endocrine stimulation tests often starts with infarction and later develops into hemorrhagic type. The initial ischemic change may 
be due to the vasoactivities of GnRH and TRH, which are commonly used. This hypothesis is supported by the report of Bernstein et al., which suggested that TRH might induce vasospasm and subsequent infarction in the pituitary tumor [1]. However, this mechanism is not applicable to all patients with pituitary apoplexy following hormone stimulating tests: Okuda et al. reported a case of the primary pituitary hemorrhage induced within ten minutes after bolus injection of TRH. Neither necrosis nor infarction was demonstrated in either the anterior pituitary lobe or the tumor in their patho- logical study [8]. However, it is worthwhile to emphasizing that the incidence of infarction preceding the hemorrhagic event is unexpectedly high in pituitary apoplexy due to hormone stimulation test.

In conclusion, headache alone is a common symptom of pituitary apoplexy after hormone stimulation test, hence it is necessary to observe patients closely at least a few hours after the test. MR imaging may help to make an earlier diagnosis of pituitary apoplexy since infarction often precedes hemorrhage and CT scan will often show no density change in the pituitary adenoma.

\section{References}

1. Bernstein $M$, Hegele RA, Gentili F, Brothers $M$, Holgate R, Sturtridge WC, Deck J (1984) Pituitary apoplexy associated with a triple bolus test. Case report. $J$ Neurosurg 61: 586-90.

2. Masago A, Ueda $Y$, Kanai H, Nagai H, Umemura $S$ (1995) Pituitary apoplexy after pituitary function test: a report of two cases and review of the literature. Surg Neurol 43(2): 158-165.

3. Chapman AJ, Williams G, Hockley AD, London DR (1985) Pituitary apoplexy after combined test of anterior pituitary function. $\mathrm{Br}$ Med J (Clin Res Ed) 291: 26.

4. Dökmetas HS, Selçuklu A, Colak R, Ünlühizarci K, Bayram F, Kelestimur F (1999) Pituitary apoplexy probably due to TRH and GnRH stimulation tests in a patient with acromegaly. $J$ Endocrinol Invest 22: 698-700.

5. Korsic M, Lelas-Bahun N, Surdonja P, Besenski N, Horvat S, Plavsic V (1984) Infarction of FSH-secreting pituitary adenoma. Acta Endocrinol (Copenh) 107: 149-154.

6. Lee DH, Chung MY, Chung DJ, Kim JM, Lee TH, Nam JH, Park CS (2000) Apoplexy of pituitary macroadenoma after combined test of anterior pituitary function. Endocr J 47: 329-333.

7. Masson EA, Atkin SL, Diver M, White MC: Pituitary apoplexy and sudden blindness following the administration of gonadotropin releasing hormone. (1993) Clin Endocrinol (Oxf) 38: 109-110.

8. Okuda O, Umezawa H, Miyaoka M (1994) Pituitary apoplexy caused by endocrine stimulation tests: a case report. Surg Neurol 42: 19-22.

9. Otsuka F, Kageyama J, Ogura T, Makino H (1998) Pituitary apoplexy induced by a combined anterior pituitary test: case report and literature review. Endocr J 45: 393-398.

10. Riedl M, Clodi M, Kotzmann H, Hainfellner JA, Schima W, Reitner A, Czech T, Luger A (2000) Apoplexy of a pituitary macroadenoma with reversible third, fourth and sixth cranial nerve palsies following administration of hypothalamic releasing hormones: MR features. Eur J Radiol 36: 1-4.

11. Sanno N, Ishii $Y$, Sugiyama M, Takagi R, Node $Y$, Teramoto A (1999) Subarachnoid Haemorrhage and Vasospasm due to Pituitary Apoplexy After Pituitary Function Tests. Acta Neurochir (Wien) 141: 10091010.

12. Szabolcs I, Kesmarki N, Bor K, Czirjak S, Dohan O, Slovik F, Goth M, Kovacs L, Ferencz A, Rimanoczy E, Szilagyi G (1997) Apoplexy of a pituitary macroadenoma as a severe complication of preoperative thyrotropin-releasing hormone (TRH) testing. Exp Clin Endocrinol Diabetes 105: 234-236.

13. Gonzalez RG, Schaefer PW, Buonanno FS, Schwamm LH, Budzik RF, Rordorf G, Wang B, Sorensen AG, Koroshetz WJ (1999) Diffusion-weighted MR imaging: diagnostic accuracy in patients imaged within 6 hours of stroke symptom onset. Radiology 210: 155-162.

14. Cardoso ER, Peterson EW (1984) Pituitary apoplexy: review Neurosurgery 14: 363-373. 